\title{
Mean platelet volume to platelet count ratio as a laboratory indicator of mortality in pneumonia following ischemic stroke
}

\author{
Rania S. Nageeb ${ }^{1 *}$ D, Mohammed M. N. Abozaid ${ }^{2}$, Ghada S. Nageeb ${ }^{3}$ and Alaa A. Omran ${ }^{4}$
}

\begin{abstract}
Background: Platelets have a vital role in antimicrobial host defenses. The objective of this study was to evaluate if increased mean platelet volume to platelet count (MPV/PC) ratio in acute ischemic stroke patients complicated with pneumonia was associated with increased mortality risk.

Methods: The current study was conducted at Zagazig University Hospitals. It included 500 acute ischemic stroke patients classified as group 1 that included 51 patients complicated with pneumonia after admission and group 2 that included the remaining 449 patients. Clinical assessment was carried out to exclude comorbid medical illnesses likely to interfere with platelet function or morphology. Laboratory investigations including MPV/PC ratio and brain imaging were carried out for all patients.

Results: There was a significant difference between both groups regarding age, National Institutes of Health Stroke Scale (NIHSS) score, and mortality within 30 days $(p=0.02,0.03,0.01)$. There was a significant difference between survivors and non-survivors of group 1 regarding to pneumonia severity index (PSI) classes IV and $V(p=0.01$ and 0.02 , respectively). Also, there was a significant difference regarding confusion, urea $\geq 7 \mathrm{mmol} / \mathrm{L}$, respiratory rater $\geq 30$ breaths/min, systolic blood pressure $\leq 90 \mathrm{mmHg}$ or diastolic blood pressure $\leq 60 \mathrm{mmHg}$, and age $\geq 65$ years at pneumonia occurrence (CURB-65) scores 3,4 , and 5 ( $p=0.03,0.02$, and 0.01 , respectively). Moreover, there was a significant difference regarding decreased GCS score at pneumonia occurrence, higher NIHSS scores, PSI, and higher MPV/PC ratio ( $p=0.01,0.01,0.028$, and 0.01 , respectively). Age $>65$ years, need for mechanical ventilation, GCS score of $>9$, PSI class $\geq$ IV, CURB-65 scores $\geq 3$, and increased MPV/PC ratio were all significantly associated with 30-day mortality in group 1 ( $p=0.03,0.01,0.001,0.04,0.01$, and 0.03 , respectively). The predictors of 30 -day mortality risk factors were GCS less than 9, increased MPV/PC ratio, and CURB-65 scores $\geq 3$ ( $p=0.001,0.05$, and 0.01, respectively).
\end{abstract}

Conclusions: Once pneumonia develops, MPV/PC ratio could be considered a significant laboratory indicator of 30-day mortality.

Keywords: Mean platelet volume to platelet count (MPV/PC) ratio, Acute ischemic stroke, Pneumonia and mortality

\section{Background}

Stroke is a major cause of disability and death worldwide (Pinto et al. 2014). About one third of stroke patients suffer from pneumonia, and this increases the morbidity and mortality of these patients (Sellars et al. 2007). Pneumonia causes the highest attributable mortality of all medical complications following stroke (Alberti et al. 2011).

\footnotetext{
* Correspondence: rnsanad@yahoo.com

${ }^{1}$ Department of Neurology, Faculty of Medicine, Zagazig University, Sharkia, Egypt

Full list of author information is available at the end of the article
}

Stroke causes neurogenic dysphagia that besides limiting food intake, it carries a greater risk of malnutrition and tracheal aspiration and triples the incidence of aspiration pneumonia (Baroni et al. 2012). This higher risk is due to the possibility of silent aspiration (without cough reflex), micro aspiration, impairment of the laryngeal closure mechanism, delayed swallow initiation, motor dysfunction of the pharynx, presence of pharyngeal residues at epiglottic valleculae, pyriform sinuses, and posterior wall of the pharynx (Nunes et al. 2012). 
Platelets have been recognized as an essential component of innate and adaptive immunity (Fitzgerald et al. 2006). Platelets contain antimicrobial peptides that exert a rapid, potent, and direct antimicrobial effect that contributes to limiting the infection (Yeaman and Bayer 2006). Thrombocytopenia is a recognized marker of poor outcomes in hospitalized patients with pneumonia (Mandell et al. 2007).

Higher values of mean platelet volume to platelet count $(\mathrm{MPV} / \mathrm{PC})$ ratio have been established in patients with different subtypes of stroke than in controls. Furthermore, mean platelet volume (MPV) has been shown to be predictive of stroke, in patients with previous cerebrovascular events. These findings lead to the hypothesis that the increase of MPV/PC might have a critical role in the outcome of stroke (Elsayed and Mohamed 2017).

The aim of the work is to investigate the association of increased mean platelet volume to platelet count (MPV/ $\mathrm{PC}$ ) ratio with increased mortality in hospitalized acute ischemic stroke patients complicated with pneumonia.

\section{Methods}

This is a cross-sectional study that was done in the period from April 2015 to March 2017. All patients meeting the inclusion criteria of this study and admitted in the stroke units of Neurology, and Internal Medicine departments in Zagazig University Hospitals, Sharkia Governorate, Egypt, during this period were included in the study. Five patients died within 3 days after admission out of 505 patients, so only 500 were included in the study, and the patient's age (mean $\pm \mathrm{SD} /$ years) was $67.3 \pm 10.2$. Fifty-one out of 500 complicated with pneumonia, those patients were classified as group 1 (37 of them were males and 14 were females), and 449 were not complicated with pneumonia, those patients were classified as group 2 (68\% of them were males and $32 \%$ were females).

\section{Ethical consideration}

A written consent was taken from all of the participants or their relatives after explaining the details of the study to them. The study was approved by the Institutional Ethical Committee of Faculty of Medicine, Zagazig University, Egypt (ZU-IRB\#4728\24-3-2017).

\section{Inclusion criteria}

Patients were eligible for inclusion in the study if they had evidence suggesting the following:

1- Acute ischemic stroke. Stroke was diagnosed clinically (as there was a new onset of neurological deficits that is corresponding to a vascular origin in the brain and lasted for more than $24 \mathrm{~h}$ ) and proved via brain imaging (computed tomography with or without magnetic resonance imaging) (Chen et al. 2013).
2- Pneumonia following acute ischemic stroke during the same hospitalization. Pneumonia was diagnosed if the acute ischemic stroke patient had relevant clinical manifestations (fever, new or increased cough, purulent tracheal secretion, or leukocytosis), positive microbiologic findings (blood, sputum cultures), and new onset of pulmonary infiltrates on chest radiography (Mirsaeidi et al. 2010).

\section{Exclusion criteria}

Patients were excluded from the study if they had comorbid medical illnesses likely to interfere with platelet function or morphology, e.g., chronic kidney disease, chronic liver diseases, and leukemia.

All patients were subjected to the following:

1- Full history taking

2- Thorough general and neurological examination

3- Laboratory investigation

Complete blood count (CBC), using automated cell counter "model XS 500i (Sysmex, Japan)," together with examination of Leishman stained peripheral blood smears for differential leukocytic count. Mean platelet volume to platelet count ratio (MPV/PC) was calculated. MPV/PC ratio was considered increased if it is more than 0.031 according to Elsayed and Mohamed, 2016 (Elsayed and Mohamed 2017). Significant leukopenia and leukocytosis were defined as white blood cell (WBC) counts of, $\leq 4000$ and $\geq 25,000$, respectively. Thrombocytopenia and thrombocytosis were defined as platelet counts, $\leq 100,000 / \mathrm{L}$ or $\geq 400,000 / \mathrm{L}$, respectively.

-Liver and kidney functions using automated analyzer "Cobas 501" (Roche diagnostics, Switzerland).

-C-reactive protein (CRP) and arterial blood gas analysis.

Alteration of gas exchange was defined as $\mathrm{PaO}_{2}$ $<60 \mathrm{mmHg}$ or $\mathrm{O}_{2}$ saturation $<90 \%$ (Mirsaeidi et al. 2010; Katz et al. 2011).

4- Imaging to confirm the presence of acute ischemic stroke and pneumonia: brain imaging (brain computed tomography with or without magnetic resonance imaging) and chest plain X-ray.

5- Scales for assessment of patients included in the study:

- Neurological scales:

A- Neurologic status was assessed by the Glasgow Coma Scale (GCS) on admission and on pneumonia occurrence (Teasdale and Jennett 1974). It can be elicited via assessment of eye opening, motor response, and verbal response. Total score ranged from 3 to 15 .

B- The clinical severity of stroke was assessed on the day of admission using the National Institutes of 
Health stroke scale (NIHSS) (Lyden et al. 2001). The NIHSS is a well-validated and commonly used stroke impairment scale that is used to evaluate the level of consciousness, language, speech, extraocular movements, visual field loss, motor strength, sensory function, coordination, and hemi-neglect. We rated the patient's ability to answer questions and perform activities. Ratings for each item are scored with 3 to 5 grades with 0 as normal. Patients were classified according to the NIHSS score into three groups: mild stroke, when the NIHSS score was $\leq 8$; moderate stroke when the NIHSS score was from 9 to 15; and severe stroke when the NIHSS score was $\geq 16$.

- Mortality risk was assessed by death in 30 days after hospital admission (Mirsaeidi et al. 2010).

- Scales for assessment of pneumonia:

1) The pneumonia severity index (PSI) score is based on age; coexisting disease, abnormal physical finding, and abnormal laboratory finding upon presentation patients were assigned to the appropriate PSI risk classes (I-V). Outpatient therapy should be considered, especially for patients in classes I and II, while patient in classes IV and V should be hospitalized (Fine et al. 1997).

2) The CURB-65 score is based on the presence of confusion, urea $\geq 7 \mathrm{mmol} / \mathrm{L}$, respiratory rater $\geq 30$ breaths/min, systolic blood pressure $\leq 90 \mathrm{mmHg}$, or diastolic blood pressure $\leq 60 \mathrm{mmHg}$, and age $\geq 65$ years at pneumonia occurrence. Patients were assigned to the appropriate CRB-65 score (1-5). A single point is given for the presence of confusion, a blood urea nitrogen value $\geq 20$, a respiratory rate $\geq 30$, a systolic blood pressure $<90 \mathrm{mmHg}$, or a diastolic blood pressure $\leq 60$, and an age $\geq 65$ years. If the score is 0 or 1 , then most likely this patient could be safely treated as an outpatient. A score of 2 might suggest closely supervised outpatient treatment or inpatient observation admission. A score of 3, 4, or 5 would usually indicate inpatient treatment (Aliberti et al. 2009).

\section{Statistical analysis}

Descriptive statistical methods were used to calculate means and standard deviation (SD). For comparisons with the continuous variables, Student's $t$ test and ANOVA were used. Comparison of categorical data was performed using the $x^{2}$ test and the Fisher exact test. Multivariate and multiple regression analyses were used. Statistical significance was made at $p$ value $<0.05$. Data were analyzed using statistical package of social science, version 14 software package (SPSS Inc., Chicago, IL, USA) (Levesque 2007).

\section{Results}

The patients were classified into two groups; their age (mean $\pm \mathrm{SD} /$ years) was $67.3 \pm 10.2$ and $59.2 \pm 25.3$ years, respectively. Twenty-four (53\%) patients died out of group 1, and 67 (15\%) patients out of group 2 died within 30 days of admission.

There was a significant difference between group 1 and group 2 regarding age $(p=0.02)$, National Institutes of Health Stroke Scale score, and number of cases that died within 30 days of admission $(p=0.03$ and 0.01 , respectively) (Table 1).

Group 1 included 51 (10.2\%) patients (those who were complicated with pneumonia). Twenty-four (53\%) patients out of them died within 30 days of admission. There was a significant difference between survivor patients and non-survivors of group 1 regarding PSI classes IV and $\mathrm{V}$ ( $p$ values were 0.01 and 0.02 , respectively). Also, there was a significant difference regarding to CURB-65 classes III, IV, and V ( $p=0.03,0.02$, and 0.01 , respectively) (Table 2 ).

Multivariate analysis comparing survivors versus non-survivors of acute ischemic stroke patients who

Table 1 Comparison between group 1 and group 2 regarding the demographic data, comorbidity and neurological scales as well as mortality risk

\begin{tabular}{|c|c|c|c|}
\hline \multirow[t]{2}{*}{ Risk factors } & $\begin{array}{l}\text { Group } 1 \\
\text { (patients with } \\
\text { pneumonia) }\end{array}$ & $\begin{array}{l}\text { Group 2 } \\
\text { (patients } \\
\text { without } \\
\text { pneumonia) }\end{array}$ & \multirow[t]{2}{*}{$p$ value } \\
\hline & $51(10 \%)$ & 449 (90\%) & \\
\hline$\overline{\text { Age (year) }}$ & $67.3 \pm 10.2$ & $59.2 \pm 25.3$ & $0.02^{*}$ \\
\hline \multicolumn{4}{|l|}{ Sex, $N(\%)$} \\
\hline Males & $37(73)$ & $305(68)$ & \multirow[t]{2}{*}{0.65} \\
\hline Females & $14(27)$ & $144(32)$ & \\
\hline Smoking & $20(39)$ & $166(37)$ & 0.41 \\
\hline \multicolumn{4}{|l|}{ Comorbidity } \\
\hline Hypertension & $36(71)$ & $323(72)$ & 0.32 \\
\hline Diabetes mellitus & $15(29)$ & $139(31)$ & 0.73 \\
\hline COPD & $6(12)$ & $72(16)$ & 0.51 \\
\hline \multicolumn{4}{|l|}{ Neurological scales } \\
\hline GCS on admission & $11.0 \pm 3.0$ & $12 \pm 3.0$ & 0.14 \\
\hline NIHSS & $17.7 \pm 5.9$ & $10.2 \pm 5.1$ & $0.03^{*}$ \\
\hline \multicolumn{4}{|l|}{ Mortality risk } \\
\hline $\begin{array}{l}\text { Death within } 30 \text { days of } \\
\text { admission }\end{array}$ & $24(53)$ & $67(15)$ & $0.01^{*}$ \\
\hline
\end{tabular}

COPD chronic obstructive pulmonary disease, GCS Glasgow Coma Scale, NIHSS National Institutes of Health Stroke Scale *Significant 
Table 2 Number and percentage of survivors versus non-survivors of group 1 regarding PSI and CURB-65 scales

\begin{tabular}{llll}
\hline $\begin{array}{l}\text { Scale of } \\
\text { assessment }\end{array}$ & $\begin{array}{l}\text { Survivors patients with } \\
\text { pneumonia 27 (53\%) }\end{array}$ & $\begin{array}{l}\text { Non-survivors patients } \\
\text { with pneumonia 24 (47\%) }\end{array}$ & $p$ value \\
\hline PSI & & $0(0)$ & 0.001 \\
Class I & $8(30)$ & $5(22)$ & 0.12 \\
Class 7 & $7(26)$ & $4(20)$ & 0.14 \\
Class III & $6(22)$ & $6(23)$ & $0.01^{*}$ \\
Class IV & $3(12)$ & $9(36)$ & $0.02^{*}$ \\
Class V & $3(12)$ & & \\
CURB-65 & & $0(0)$ & 0.14 \\
Score 1 & $5(18)$ & $6(25)$ & 0.13 \\
Score 2 & $8(30)$ & $9(37)$ & $0.03^{*}$ \\
Score 3 & $8(30)$ & $6(25)$ & $0.02^{*}$ \\
Score 4 & $5(18)$ & $3(13)$ & $0.01^{*}$ \\
\hline Score 5 & $1(4)$ & & \\
\hline
\end{tabular}

PSI pneumonia severity index

*Significant

developed pneumonia (group 1), according to risk factors of 30 days mortality, there was significant difference regarding lower GCS score at pneumonia occurrence, higher National Institutes of Health Stroke Scale scores, $\mathrm{PSI}$, and higher MPV/PC ratio $(p=0.01,0.01,0.028$, and 0.01 , respectively) (Table 3 ).

In multiple regression analysis for 30-day mortality risk in group 1 age $>65$ years, need for mechanical ventilation, GCS score of less than 9, high-PSI risk class $\geq \mathrm{IV}$, CURB-65 scores $\geq 3$, and increased mean platelet volume/ platelet count ratio were all significantly associated with 30 -day mortality ( $p=0.03,0.01,0.001,0.04,0.01$, and 0.03 , respectively) (Table 4$)$.

In logistic regression analysis for detection of 30-day mortality risk in non-survivors of group 1 , the most significant 30-day mortality risk factors were GCS $<9$ at pneumonia occurrence, increased $\mathrm{MPV} / \mathrm{PC}$ ratio, and CURB-65scores $\geq 3$ ( $p=0.001,0.05$, and 0.04 , respectively) (Table 5).

\section{Discussion}

Although mortality is encountered in pneumonia following ischemic stroke, there is no specific laboratory investigative tool for this entity (Chen et al. 2013). So the aim of the present study was to investigate the association of increased mean platelet volume to platelet count (MPV/PC) ratio with increased 30-day mortality in hospitalized acute ischemic stroke patients complicated with pneumonia.

There was a significant difference between group 1 and group 2 regarding age, National Institutes of Health Stroke Scale score (NIHSS), and number of cases that died within 30 days of admission. This is in agreement
Table 3 Multivariate analysis comparing survivors versus nonsurvivors of group 1 according to risk factors of 30 day mortality

\begin{tabular}{|c|c|c|c|}
\hline $\begin{array}{l}\text { Risk factors of } \\
\text { 30-day mortality }\end{array}$ & $\begin{array}{l}\text { Survivors of } \\
\text { group } 1 \\
(n=27)\end{array}$ & $\begin{array}{l}\text { Non-survivors } \\
\text { of group } 1 \\
(n=24)\end{array}$ & $p$ value \\
\hline $\begin{array}{l}\text { Time from stroke to pneumonia } \\
\text { onset/days }\end{array}$ & $9 \pm 2$ & $12 \pm 4$ & 0.921 \\
\hline \multicolumn{4}{|c|}{ Scales for assessment of ischemic stroke } \\
\hline GCS on admission & $12 \pm 3$ & $11 \pm 3$ & 0.461 \\
\hline $\begin{array}{l}\text { GCS at pneumonia } \\
\text { occurrence }\end{array}$ & $11 \pm 3$ & $8 \pm 2$ & $0.01^{*}$ \\
\hline NIHSS & $9 \pm 4$ & $18 \pm 6$ & $0.01^{*}$ \\
\hline $\begin{array}{l}\text { PSI scales for assessment } \\
\text { of pneumonia severity }\end{array}$ & $92 \pm 36$ & $124 \pm 37$ & $0.028^{*}$ \\
\hline \multicolumn{4}{|l|}{ Clinical findings } \\
\hline Body temperature $\left({ }^{\circ} \mathrm{C}\right)$ & $37 \pm 1$ & $38 \pm 0.8$ & 0.580 \\
\hline Respiratory rate & $23 \pm 5$ & $26 \pm 6$ & 0.059 \\
\hline Heart rate & $70 \pm 20$ & $75 \pm 15$ & 0.376 \\
\hline Systolic blood pressure & $149 \pm 20$ & $130 \pm 30$ & 0.146 \\
\hline \multicolumn{4}{|l|}{ Laboratory results } \\
\hline WBC count $/ \mathrm{mm} 3$ & $11,641 \pm 4199$ & $10,885 \pm 3960$ & 0.583 \\
\hline MPV/PC ratio & $0.030 \pm 0.607$ & $0.06 \pm 0.01$ & $0.01^{*}$ \\
\hline Blood urea nitrogen, mg/dL & $25 \pm 14$ & $30.5 \pm 21$ & 0.382 \\
\hline Serum creatinine, mg/dL & $1.5 \pm 1$ & $2.0 \pm 3$ & 0.466 \\
\hline
\end{tabular}

GCS Glasgow Coma Scale, NIHSS National Institutes of Health Stroke Scale, PSI pneumonia severity index, MPV/pc ratio mean platelet volume/platelet count ratio *Significant

with a previous study of Mirsaeidi and colleagues (Mirsaeidi et al. 2010) who found that age $>65$ years was significantly associated with 30 -day mortality risk in patients with pneumonia.

Thirty day mortality was significantly associated with PSI risk classes $\geq$ IV and CURB-65 scores $\geq 3$ in our ischemic stroke patients with pneumonia, and these results are consistent with Mirsaeidi and colleagues (Mirsaeidi et al. 2010) and Chen and colleagues (Chen et al. 2013). Also, Golcuk and colleagues (Golcuk et al. 2015) confirmed that the CURB-65 score could independently predict mortality in patients with acquired pneumonia.

Moreover, in the present study, patients who survived from pneumonia had statistically significant better scores in GCS score at pneumonia occurrence, NIHSS scores, PSI score, and MPV/PC ratio than non-survivors. This is in agreement with the findings of Chen and colleagues (Chen et al. 2013) who stated that lower GCS scores on the day of pneumonia onset and higher NIHSS scores were significant risk factors for 30-day mortality in patients complicated with pneumonia following acute ischemic stroke. Also, these findings met with the findings of Elsayed and Mohamed (Elsayed and Mohamed 2017) who found that ischemic stroke patients had significantly 
Table 4 Multiple regression analysis for predictors of 30-day mortality in group 1

\begin{tabular}{|c|c|c|c|c|}
\hline Predictors of 30-day mortality & Group 1 & & 95\% confidence intervals & $p$ value \\
\hline \multirow[t]{2}{*}{ Age $>65$ years } & Non-survivors & $12(54 \%)$ & $0.833-0.987$ & $0.03^{*}$ \\
\hline & Survivors & $12(46 \%)$ & & \\
\hline \multirow[t]{2}{*}{ Sex (males/females) } & Non-survivors & $19(51 \%) / 18(49 \%)$ & $0.63-1.34$ & 0.34 \\
\hline & Survivors & $8(52 \%) / 6(48 \%)$ & & \\
\hline \multirow[t]{2}{*}{ Smoking } & Non-survivors & $12(60 \%)$ & $0.13-1.25$ & 0.25 \\
\hline & Survivors & $8(40 \%)$ & & \\
\hline \multirow[t]{2}{*}{ Mechanical ventilation } & Non-survivors & $8(33 \%)$ & $0.35-0.26$ & $0.01^{*}$ \\
\hline & Survivors & $6(22 \%)$ & & \\
\hline \multirow[t]{2}{*}{ GCS at pneumonia occurrence $<9$} & Non-survivors & $15(63 \%)$ & $11.12-21.30$ & $0.001^{*}$ \\
\hline & Survivors & $10(37 \%)$ & & \\
\hline \multirow[t]{2}{*}{ Pleural effusion in CXR } & Non-survivors & $11(46 \%)$ & $0.47-1.38$ & 0.99 \\
\hline & Survivors & $12(44 \%)$ & & \\
\hline \multirow[t]{2}{*}{ Pulmonary infiltrates in CXR } & Non-survivors & $11(46 \%)$ & $0.36-1.14$ & 0.224 \\
\hline & Survivors & $12(44 \%)$ & & \\
\hline \multirow[t]{2}{*}{ PSI risk class $\geq 4$} & Non-survivors & $15(63 \%)$ & $1.095-2.364$ & $0.04^{*}$ \\
\hline & Survivors & $6(22 \%)$ & & \\
\hline \multirow[t]{2}{*}{ CURB-65 scores $\geq 3$} & Non-survivors & 18 (75\%) & $1.23-2.99$ & $0.01^{*}$ \\
\hline & Survivors & $14(52 \%)$ & & \\
\hline \multirow[t]{2}{*}{ Increased MPV/PC ratio } & Non-survivors & $16(67 \%)$ & $2.9-2.23$ & $0.03^{*}$ \\
\hline & Survivors & $8(30 \%)$ & & \\
\hline
\end{tabular}

GCS Glasgow Coma Scale, NIHSS National Institutes of Health Stroke Scale, CXR chest radiograph, PSI pneumonia severity index, MPV/pc ratio mean platelet volume/platelet count ratio

*Significant

higher MPV/PC ratio that could be used as surrogate laboratory markers for early detection and risk stratification of cerebrovascular stroke. Bharosay and colleagues (Bharosay et al. 2016) stated that steady-state inverse, and nonlinear relationship between MPV and platelet count (PC), has been observed.

The need for mechanical ventilation and the presence of thrombocytosis were significantly associated with 30-day mortality in patients with acquired pneumonia according to the findings of Mirsaeidi and colleagues (Mirsaeidi et al. 2010). This was concomitant with our results as the need for mechanical ventilation and the increased mean platelet volume/platelet count ratio were significantly associated with 30 -day mortality in our patients.

Table 5 Logistic regression analysis for detection of 30-day mortality risk in pneumonia complicating ischemic stroke patients in non-survivors

\begin{tabular}{lll}
\hline Risk factor of 30-day mortality & $95 \%$ confidence intervals & $p$ value \\
\hline GCS $<9$ at pneumonia occurrence & $1.25-2.35$ & $0.001^{*}$ \\
Increased MPV/PC ratio & $2.13-2.138$ & $0.05^{*}$ \\
CURB-65 scores $\geq 3$ & $1.43-1.93$ & $0.01^{*}$ \\
\hline
\end{tabular}

GCS Glasgow Coma Scale, MPV/pc ratio mean platelet volume/platelet count ratio *Significant
Authors of the present study found that the most significant 30-day mortality risk factors were GCS $<9$ at pneumonia occurrence, increased MPV/PC ratio, and CURB-65 scores $\geq 3$. These observations were in agreement with Elsayed and Mohamed (Elsayed and Mohamed 2017) who stated that the high discriminative value of MPV/PC ratio could predict severe ischemic stroke based on Rankin score $\geq 3$ from a mild stroke. Also, Golcuk and colleagues (Golcuk et al. 2015) concluded that a combination of CURB-65 score and MPV can enhance the predictive accuracy of mortality in patients with acquired pneumonia.

\section{Conclusions}

Once pneumonia develops in acute ischemic stroke patients, MPV/PC ratio could be considered as a significant laboratory marker.

\section{Abbreviations}

COPD: Chronic obstructive pulmonary disease; CURB-65 score: Confusion, urea $\geq 7 \mathrm{mmol} / \mathrm{L}$, respiratory rater $\geq 30$ breaths $/ \mathrm{min}$, blood pressure $\leq 90 \mathrm{mmHg}$ systolic or $\leq 60 \mathrm{mmHg}$ diastolic, and age $\geq 65$ years at pneumonia occurrence; CXR: Chest radiograph; GCS: Glasgow Coma Scale; MPV: Mean platelet volume; MPV/PC: Mean platelet volume to platelet count ratio; NIHSS: National Institutes of Health Stroke Scale; PSI score: Pneumonia severity index score; WBC: White blood cell 


\section{Acknowledgements}

The work was carried out in Neurology, Internal Medicine, Clinical Pathology, and Chest Departments, Faculty of Medicine, Zagazig University. The authors acknowledge the subjects for their participation and cooperation in this study.

\section{Funding}

There is no source of funding for the research.

\section{Availability of data and materials}

The data supporting the results of this article are included within the article (and its additional file(s)).

\section{Authors' contributions}

$\mathrm{RN}, \mathrm{MA}, \mathrm{GN}$, and $\mathrm{AO}$ carried out the work. RN designed the study, coordinated with the research team, and wrote the manuscript. RN and MA collected the patients and gathered the clinical data. GN statistically analyzed and reviewed the manuscript. AO helped the laboratory work of the study. All authors were involved in drafting the article or revising it critically for important intellectual content, and all authors approved the final version to be published.

\section{Ethics approval and consent to participate}

The study was approved by the institutional ethics committee of Faculty of Medicine, Zagazig University (ZU-IRB\#4728\24-3-2017). A written consent was taken from all of the participants after explaining the details, benefits, and risks to them.

\section{Consent for publication}

Consent for publication has been obtained from the participants involved in the study to report their individual patient data.

\section{Competing interests}

The authors declare that they have no competing interests.

\section{Publisher's Note}

Springer Nature remains neutral with regard to jurisdictional claims in published maps and institutional affiliations.

\section{Author details}

'Department of Neurology, Faculty of Medicine, Zagazig University, Sharkia, Egypt. ${ }^{2}$ Department of Chest, Faculty of Medicine, Zagazig University, Sharkia, Egypt. ${ }^{3}$ Department of Rheumatology \& Rehabilitation, Faculty of Medicine, Zagazig University, Sharkia, Egypt. ${ }^{4}$ Department of Clinical Pathology, Faculty of Medicine, Zagazig University, Sharkia, Egypt.

Received: 20 October 2017 Accepted: 17 September 2018

Published online: 26 September 2018

\section{References}

Alberti A, Agnelli G, Caso V, Venti M, Acciarresi M, D'Amore C, et al. Nonneurological complications of acute stroke: frequency and influence on clinical outcome. Intern Emerg Med. 2011;6:119-223.

Aliberti S, Brock GN, Peyrani P, Blasi F, Ramirez JA, the Community-Acquired Pneumonia Organization. The pneumonia severity index and the CRB-65 in cancer patients with community-acquired pneumonia. INT. J TUBERC LUNG DIS. 2009;13:1550-6.

Baroni AF, Fábio SRC, Dantas RO. Risk factors for swallowing dysfunction in stroke patients. Arq Gastroenterol. 2012;49:118-24

Bharosay A, Bharosay W, Bandyopadhyay D, Choubey R, Varma V, Saxena K, Varma A. Neurological worsening and association between LDL, HDL ratio, mean platelet volume and platelet count in cerebrovascular ischemic stroke. Int J Health Sci Res. 2016;6(4):209-15.

Chen LF, Chang CY, Hsu LC, Tsai PH, Chang SJ, Chang SC, et al. Bacterial pneumonia following acute ischemic stroke. J ChinMed Associat. 2013;76:78-82.

Elsayed AM, Mohamed GA. Mean platelet volume and mean platelet volume/ platelet count ratio as a risk stratification tool in the assessment of severity of acute ischemic stroke. Alex J Med. 2017;53:67-70.

Fine MJ, Auble TE, Yealy DM, Hanusa BH, Weissfeld LA, Singer DE, et al. A prediction rule to identify low-risk patients with community acquired pneumonia. N Engl J Med. 1997;336:243-50.

Fitzgerald JR, Foster TJ, Cox D. The interaction of bacterial pathogens with platelets. Nat Rev Microbiol. 2006:4:445-57.
Golcuk Y, Golcuk B, Bilge A, lrik M, Dikmen O. Combination of mean platelet volume and the CURB-65 score better predicts 28-day mortality in patients with community-acquired pneumonia. Americ J of Emerg Med. 2015;33:648-52.

Katz JN, Kolappa KP, Becker RC. Beyond thrombosis: the versatile platelet in critical illness. Chest. 2011;139:658-68.

Levesque R. SPSS programming and data management: a guide for SPSS and SAS users. 4th ed. Chicago: SPSS Inc.; 2007.

Lyden PD, Lu M, Levine SR, Brott TG, Broderick J, the NINDS rtPA stroke study group. A modified National Institutes of Health Stroke Scale for use in stroke clinical trials preliminary reliability and validity. Stroke. 2001;32:1310-7.

Mandell LA, Wunderink RG, Anzueto A, Bartlett JG, Campbell GD, Dean NC, et al. Infectious Diseases Society of America/American Thoracic Society consensus guidelines on the management of community acquired pneumonia in adults. Clin. Infect. Dis. 2007;44(2):27-72.

Mirsaeidi M, Peyrani P, Aliberti S, Filardo G, Bordon J, Blasi F, et al. Thrombocytopenia and thrombocytosis at time of hospitalization predict mortality in patients with community-acquired pneumonia. Chest. 2010;137:416-20.

Nunes MCA, Jurkievicz AL, Santos RS, Furkim AM, Massi G, Pinto GSA, et al. Correlation between brain injury and dysphagia in adult patients with stroke. Int Arch Otorhinolaryngol. 2012;16:313-21.

Pinto G, Zétola V, Lange M, Gomes G, Nunes CM, Hirata G, et al. Program to diagnose probability of aspiration pneumonia in patients with ischemic stroke. Int. Arch. Otorhinolaryngol. 2014;18:244-8,

Sellars C, Bowie L, Bagg J, Sweeney MP, Miller H, Tilston J, et al. Risk factors for chest infection in acute stroke. Stroke. 2007;38:2284-91.

Teasdale $G$, Jennett B. Assessment of coma and impaired consciousness. A practical scale. Lancet. 1974;304(7872):81-4.

Yeaman MR, Bayer AS. Antimicrobial peptides versus invasive infections. Curr Top Microbiollmmunol. 2006;306:111-52.

\section{Submit your manuscript to a SpringerOpen ${ }^{\circ}$ journal and benefit from:}

- Convenient online submission

- Rigorous peer review

- Open access: articles freely available online

High visibility within the field

- Retaining the copyright to your article

Submit your next manuscript at $\boldsymbol{\nabla}$ springeropen.com 